\title{
Article
}

\section{Salification Controls the In-Vitro Release of Theophylline}

\author{
Laura Baraldi $^{1,2}$, Luca Fornasari ${ }^{2}$ (D), Irene Bassanetti ${ }^{2}$, Francesco Amadei ${ }^{2}$, Alessia Bacchi ${ }^{1,3}$ and \\ Luciano Marchiò 1,3,*iD
}

1 Dipartimento di Scienze Chimiche, della Vita e della Sostenibilità Ambientale, Università di Parma, 43124 Parma, Italy; laura.baraldi@unipr.it (L.B.); alessia.bacchi@unipr.it (A.B.)

2 Preclinical Analytics and Early Formulations Department, Chiesi Farmaceutici S.p.A., Largo Belloli, 43123 Parma, Italy; 1.fornasari@chiesi.com (L.F.); i.bassanetti@chiesi.com (I.B.); f.amadei@chiesi.com (F.A.)

3 Biopharmanet TEC, Tecnopolo Padiglione 33, Università di Parma, 43124 Parma, Italy

* Correspondence: luciano.marchio@unipr.it

check for updates

Citation: Baraldi, L.; Fornasari, L.; Bassanetti, I.; Amadei, F.; Bacchi, A.; Marchiò, L. Salification Controls the In-Vitro Release of Theophylline. Crystals 2022, 12, 201. https:// doi.org/10.3390/cryst12020201 Academic Editors: Changquan Calvin Sun and Junpei Yamanaka

Received: 6 December 2021 Accepted: 27 January 2022 Published: 29 January 2022

Publisher's Note: MDPI stays neutral with regard to jurisdictional claims in published maps and institutional affiliations.

Copyright: () 2022 by the authors. Licensee MDPI, Basel, Switzerland. This article is an open access article distributed under the terms and conditions of the Creative Commons Attribution (CC BY) license (https:// creativecommons.org/licenses/by/ $4.0 /)$.

\begin{abstract}
Sustained released formulation is the most used strategy to control the efficacy and the adverse reactions of an API (active pharmaceutical ingredient) with a narrow therapeutic index. In this work, we used a different way to tailor the solubility and diffusion of a drug. Salification of Theophylline with Squaric Acid was carried out to better control the absorption of Theophylline after administration. Salification proved to be a winning strategy decreasing the dissolution of the APIs up to $54 \%$ with respect to Theophylline. Most importantly, this was accomplished in the first $10 \mathrm{~min}$ of the dissolution process, which are the most important for the API administration. Two polymorphs were identified and fully characterized. Theophylline squarate was discovered as trihydrate (SC-XRD) and as a metastable anhydrous form. Indeed, during the Variable Temperature-XRPD experiment, the trihydrate form turned back into the two starting components after losing the three molecules of water. On the other hand, the synthesis of the trihydrate form was observed when a simple mixing of the two starting components were exposed to a high humidity relative percentage $(90 \% \mathrm{RH})$.
\end{abstract}

Keywords: xanthines; theophylline; squaric acid; controlled release; dissolution; solubility

\section{Introduction}

Xanthines like theophylline, caffeine, and theobromine are a group of alkaloids, which act as mild stimulants and as bronchodilators. Theophylline in particular has an antiinflammatory effect in asthma and chronic obstructive pulmonary disease (COPD) at lower concentrations [1].

Theophylline's mechanism of action implies the inhibition of phosphodiesterase, which is responsible for the smooth muscle relaxation. However, theophylline is also known for its narrow therapeutic index $(30-100 \mu \mathrm{M})$ caused by a remarkably low selectivity. Indeed, a concentration of $110 \mu \mathrm{M}$ already leads to a wide range of adverse reactions such as nausea, vomiting, metabolic acidosis, and arrhythmias [2]. For this reason, despite being an effective API, theophylline is not considered the first choice in the treatment of asthma. It is usually administered orally in slow-release preparations for chronic treatment in combination with a short acting $\beta 2$-agonist, long acting $\beta 2$ agonist, or an inhaled corticosteroid [3-5].

Lots of significant work has been done in the formulation field to optimize the theophylline absorption profile. Pezoa et al. [6], Rodrigues et al. [7], and Jian et al. [8] are just a few examples of the huge effort that has been done so far aiming at a better in-vivo performance. Formulations were modified using excipients like Eudragit or involving nanoparticles to have a prolonged effect and better control on the adverse reactions [9]. While optimizing a formulation many aspects must be taken into account [10], such as the role of every single component and how they influence the final release or the scale up. The interactions between excipient-excipient and drug-excipient are also to be considered. 
Hydrolysis of the drug, ion interactions leading to new insoluble forms, or other physical interactions like adsorption of the API onto the surface of excipients might be significant drawbacks, resulting from the interactions between excipients and drugs [11].

In this work, we used a different strategy to tune the properties of this active pharmaceutical ingredient: a salification of theophylline with squaric acid was carried out to optimize its solubility, dissolution rate, and diffusion. Squaric acid is a strong acid belonging to the family of oxocarbons [12]. It has been studied extensively for its peculiar physical properties [13] and for its use in the synthesis of dyes [14,15]. In the pharmaceutical industry, squaric acid derivatives have attracted interest for their potential use as topical immunosensitizers [16], enzyme inhibitors, and receptor antagonists [17]. However, to the best of our knowledge, squaric acid has never been studied in the formation of API salts. From a crystal engineering perspective, the features that guided the selection of this acid as salt-former are its strong acidity $\left(\mathrm{pK}_{\mathrm{a} 1}=0.6, \mathrm{pK}_{\mathrm{a} 2}=3.4\right)$ [18], its highly symmetric character, and the well-established tendency to form layered H-bonded assemblies $[19,20]$, that should couple effectively with mostly planar molecules such as xanthines.

Usually, when looking for a new salt to improve the pharmacokinetic properties of an API, hydrate forms are unwelcome. Hydrates usually have a higher thermodynamic stability leading to a slower dissolution profile [21,22]. In this peculiar case, the hydrate form would turn useful, providing a better control of the released drug. Moreover, salification might turn to be easier and quicker with respect to the formulation development. Indeed, once the salt is synthesized already known manufacturing processes can be applied, yielding standard tablets or capsules for instance. Some theophylline salts have already been studied [23,24]. Furthermore, some systems have been designed with the aim of improving bioactivity [25] or stability [26], however, in both cases, the salts resulted more soluble than theophylline alone. Hence, salification has never been applied to theophylline with the purpose to ameliorate the therapeutic index issues

\section{Materials and Methods}

\subsection{General}

Theophylline, Squaric acid, Tetrahydrofurane (THF), Diethyl Ether, and Ethanol were used as received from MERCK-Sigma Aldrich (Taufkirchen, Germany, EU). Solvents were commercially available and used without any other purification. Water was used after filtration with MilliQ Advantage A10 technology from Millipore (MERCK-Sigma Aldrich (Darmstadt, Germany)).

\subsection{Theophylline Squarate}

The bulk powder of the hydrate form (TS3w) was obtained via LAG (liquid assisted grinding). Theophylline and Squaric Acid were weighed in an equimolar ratio (1:1, total mass $163 \mathrm{mg}$ ), the sample was transferred to a $4.0 \mathrm{~mL}$ vial with three grinding balls $(5 \mathrm{~mm}$ $\phi$, zirconia type) and the desired solvent was added ( $20 \mu \mathrm{L}$ of water Milli-Q). Then, the mixture was ground for $1 \mathrm{~h}$ using a multi-sample vibrating ball mill (Pulverisette 6-Fritsch, Germany) under a rotational speed of $300 \mathrm{rpm}$ and a temperature of $25^{\circ} \mathrm{C}$.

Along with TS3w, an anhydrous form was obtained (TSan). In order to obtain TSan, Theophylline (100 mg) and Squaric Acid (63 mg) were both dissolved in water (10 ml) at room temperature and lyophilized. An amorphous powder was obtained and crystallized through slurry in acetone $10 \mathrm{mg} / \mathrm{mL}$ at room temperature for three days.

\subsection{Single-Crystal X-ray Diffraction (SC-XRD)}

Crystals of TS3w suitable for SC-XRD analysis were obtained alternatively from slow evaporation of an EtOH solution of TS3w and from stratification of diethylether over an EtOH solution of TS3w.

Single crystal data were collected at $220 \mathrm{~K}$ with a Bruker (US) D8 Venture diffractometer equipped with a Photon II detector, using a $\mathrm{CuK} \alpha$ microfocus radiation source $(\lambda=1.54184 \AA)$. The intensity data were integrated from several series of exposure frames 
covering the sphere of reciprocal space. Data reductions were performed with APEX3 (III). Absorption corrections were applied using the program SADABS [27]. The structures were solved by intrinsic phasing with the program SHELXT (1.0.825/28 January 2017). Fourier analysis and refinement were performed by the full-matrix least-squares methods based on $\mathrm{F}^{2}$ using SHELXL-2017 [28,29] implemented in Olex2 software (1.3) [30]. Non-H atoms were refined anisotropically, $\mathrm{H}$ atoms were placed in calculated positions and refined with a riding model. Crystallographic data can be found in Supplementary Materials, Table S1.

CCDC 2124344 contains the supplementary crystallographic data for this paper.

\subsection{X-ray Powder Diffraction (XRPD)}

The crystalline state of samples was investigated by X-ray powder diffraction (XRPD) with an Emyrean Panalytical (UK) V 2.0 instrument equipped with $\mathrm{Cu}$ radiation source. Samples were placed on zero background sample holders. The measurements were performed in reflection mode with 2 Theta scans from 1.5 to $45^{\circ}$, step size $0.02^{\circ}$, soller slit $0.02 \mathrm{rad}$, divergence slit $1 / 8^{\circ}$, antiscatter slit $1 / 4^{\circ}$. The variable temperature and humidity XRPD analyses were carried out with an Anton Paar (Austria) $\mathrm{CHC}+$ camera equipped with CCU100 temperature control and an MHG-32 humidity generator. The measurements were performed in reflection mode, 2Theta scan from 1.5 to $45^{\circ}$, step size $0.02^{\circ}$, soller slit $0.02 \mathrm{rad}$, divergence slit $1 / 8^{\circ}$, antiscatter slit $1 / 4^{\circ}$.

\subsection{Differential Scanning Calorimetry (DSC)}

DSC analyses were performed using a routinely calibrated TA Instruments differential scanning calorimeter Discovery equipped with a computer analyzing system (TRIOS). Indium standard and a sapphire disk were used for temperature/enthalpy calibration and heat capacity calibration, respectively. The system was equipped with a refrigerated cooling system (RCS90) accessory under a dry nitrogen purge (50 mL/min). About 1-5 mg of each sample were placed into a Tzero Aluminum hermetic DSC pan covered with a lid. The sample cell was equilibrated at $0{ }^{\circ} \mathrm{C}$ and heated under a nitrogen purge $(50 \mathrm{~mL} / \mathrm{min})$. All samples were given similar thermal histories by linearly heating to $300{ }^{\circ} \mathrm{C}$ at a heating rate of $10^{\circ} \mathrm{C} / \mathrm{min}$.

\subsection{Thermogravimetric Analysis (TGA)}

TGA analyses were performed using a TA Instruments Discovery equipped with a computer analyzing system (TRIOS V4.3). About $2 \mathrm{mg}$ of each sample were placed into a Platinum $100 \mu \mathrm{L}$ pan. The heating rate was $10^{\circ} \mathrm{C} / \mathrm{min}$ to $300^{\circ} \mathrm{C}$.

\subsection{Dynamic Vapour Sorption (DVS)}

Moisture sorption/desorption data were collected on a TA Instruments (New Castle, DE, USA) Vapor Sorption Analyzer Q5000SA. First step: sorption data were collected in the range of $40 \%$ to $90 \%$ relative humidity. Second step: desorption, sorption, and desorption data were collected over a range of $0 \%$ to $90 \%$ relative humidity $(\mathrm{RH})$ at $10 \% \mathrm{RH}$ intervals under a nitrogen purge. Samples were not dried prior to the analysis. Equilibrium criteria used for analyses were less than $0.100 \%$ weight change in $20 \mathrm{~min}$, with a maximum equilibration time of $1 \mathrm{~h}$ if the weight criterion was not met. Data were not corrected for the initial moisture content of the samples. $\mathrm{NaBr}$ was used for humidity verification.

\subsection{Dissolution Studies}

Dissolution studies of theophylline and theophylline squarate trihydrate were carried out using water MilliQ ( $\mathrm{pH}$ 5.5) at room temperature. 6 suspensions at a concentration of $1.5 \mathrm{mg} / \mathrm{mL}$ were prepared for both theophylline and theophylline squarate trihydrate. Each suspension corresponds to a different time point (0-2 min-4 min-6 $\min -8 \mathrm{~min}-10 \mathrm{~min})$. From each sample, $200 \mu \mathrm{L}$ were taken at the corresponding time point and filtered. $20 \mu \mathrm{L}$ from each taken solution were then diluted (1:10) with $\mathrm{H}_{2} \mathrm{O}$ and injected. 
Ultra-high-performance liquid chromatography with ultraviolet detection (UHPLCUV) was used for quantitative analysis of the dissolved drug which absorbs UV-light in the range of 200-290 $\mathrm{nm}$ with an absorbance maximum at $254 \mathrm{~nm}$. UHPLC-UV analysis was conducted on a Waters Acquity UPLC system (Milford, MA, USA) that was connected to a diode array detector and equipped with a reversed phase Kinete ${ }^{\circledR}$ EVO C8 LCcolumn $\left(100 \times 2.1 \mathrm{~mm}\right.$; particle size $1.7 \mu \mathrm{m}$; pore size $100 \AA$, Phenomenex $\left.{ }^{\circledR}\right)$. The mobile phase consisted of $25 \mathrm{mM}$ of ammonium formiate buffer $(\mathrm{pH} 3)$ and $0.1 \%$ formic acid in acetonitrile, the flow rate was $0.5 \mathrm{~mL} / \mathrm{min}$ and the column oven was set to $50{ }^{\circ} \mathrm{C}$. The injection volume was $2 \mu \mathrm{L}$.

\section{Results}

\subsection{Theophylline Squarate}

\subsubsection{Single Crystal Molecular Structure}

The asymmetric unit comprises one molecule of theophylline, one molecule of squaric acid, and three molecules of water (See Figure S8). Theophylline exchanges four HBs with two squarate anions via the N11, N21, and C11 atoms (N11 ‥ O12, $2.63 \AA$; N21 ‥ O32, $2.64 \AA$; $\mathrm{C} 11 \cdots \mathrm{O} 22,3.03 \AA$; $\mathrm{C} 11 \cdots \mathrm{O} 42,3.12 \AA$ ). Interestingly, $\mathrm{C} 11$ forms a bifurcated HB with two squarate anions. In addition, $\mathrm{O} 11$ and $\mathrm{O} 21$ of Theophylline act as $\mathrm{HB}$ acceptors with respect to two symmetry-related O1W water molecules $(\mathrm{O} 21 \cdots \mathrm{O} 1 \mathrm{~W}, 2.77 \AA$; O11 ... O1W, $2.92 \AA)$. The two components interact through a HBs connectivity involving two water molecules (O1W and O2W). O1W exchanges three HBs, two as a donor, as already described, and one as acceptor (range $2.74 \AA-2.92 \AA$ ), O2w exchanges three HBs, two as a donor, and one as acceptor (range $2.53 \AA-2.82 \AA$ ). O3W forms two HBs as a donor with a symmetry related molecule $(3.31 \AA)$ and with O32 of a squarate anion $(2.84 \AA)$, respectively, and it accepts HBs from O2W (2.82 $\AA$ ), Figure 1. On the other hand, O3w is located into a channel like cavity and, according to the long HB distances, it is more loosely bound to the surrounding molecules, Figure S8.

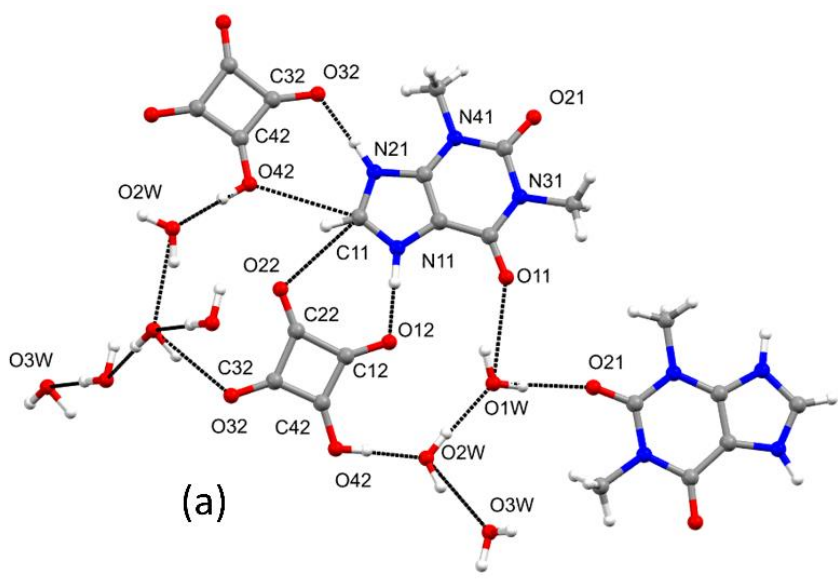

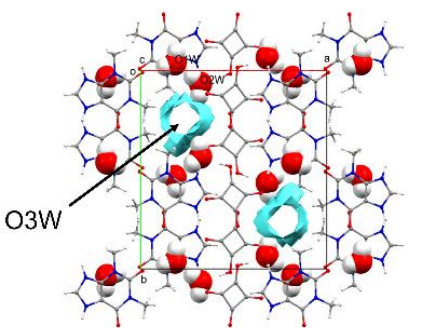

(b)

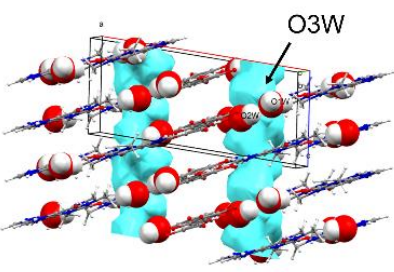

(c)

Figure 1. Molecular structure of Theophylline squarate trihydrate with thermal ellipsoids plotted at the $30 \%$ probability level, highlighting the intermolecular connection (a). The water channel hosting the water molecule $\mathrm{O} 3 \mathrm{~W}$ is showed along the c-axes $(\mathbf{b})$ and along a diagonal direction (c). 
$\mathrm{C}-\mathrm{O}$ and $\mathrm{C}-\mathrm{C}$ bond lengths of the $\mathrm{C}_{4}$ ring of the squarate are quite indicative of the resonance condition because of the mono-anion formation, Figure 2.

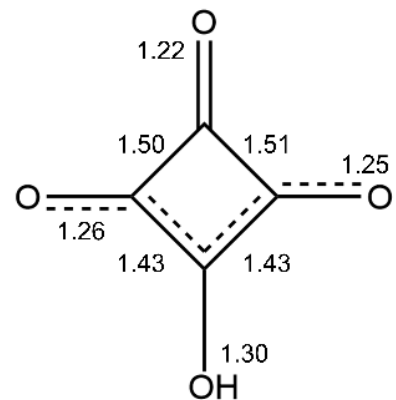

Figure 2. Resonance structure of monodeprotonated squarate anion with bond distance $(\AA)$ indicated.

The C42-O42 bond is the longest being the only pure $\mathrm{C}-\mathrm{O}$ single bond. $\mathrm{C} 22-\mathrm{O} 22$ is the shortest being the only pure double bond. The other two $\mathrm{C}-\mathrm{O}$ bonds have an intermediate length having a partial double bond character [31]. It follows that C32-C42 and C42-C12 are the shortest covalent bonds associated with a partial double bond.

There are some intrinsic features in the network that the water molecules establish. As previously discussed, $\mathrm{O} 3 \mathrm{~W}$ is located in a channel that runs parallel to the $c$-axis (see Figure $1 b, c)$. O3W is the most loosely bound to the surroundings and it would be most likely the first molecule leaving the structure upon dehydration. This is also confirmed by the calorimetric analysis as discussed below.

\subsubsection{Thermal and Structural Characterization}

VT-XRPD (Variable temperature-X-ray powder diffraction) experiment was carried out on TS3w. The temperature was slowly increased from to $25^{\circ} \mathrm{C}$ to $70{ }^{\circ} \mathrm{C}-120{ }^{\circ} \mathrm{C}-155^{\circ} \mathrm{C}-190{ }^{\circ} \mathrm{C}$ as shown in Figure 3. Once water is removed $\left(120^{\circ} \mathrm{C}\right)$ the structure does not collapse and does not lead to the anhydrous form TSan either. It dissociates into the starting components. A new diffraction line appears at high temperature $\left(155^{\circ} \mathrm{C}-190^{\circ} \mathrm{C}\right)$ belonging to a different theophylline polymorph (elusive form V) [32]. However, at the end of the experiment theophylline can be easily detected and no diffraction lines belonging to TS3w pattern is observed.

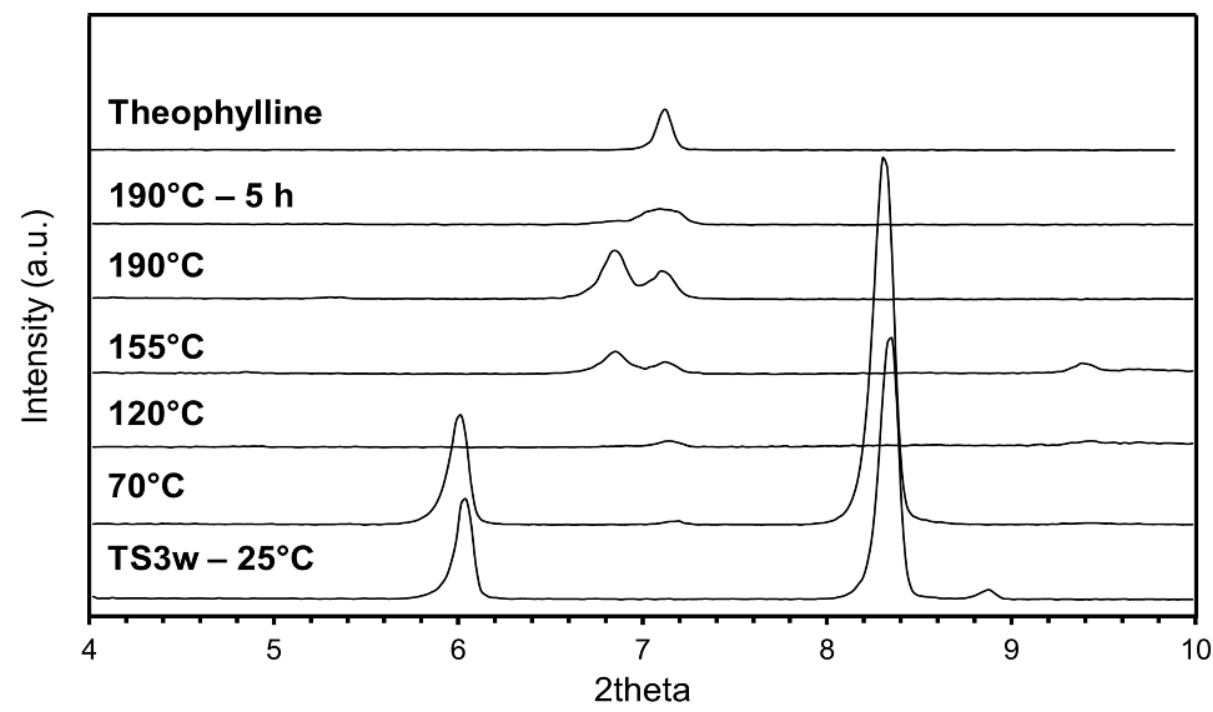

Figure 3. VT-XRPD of Theophylline Squarate trihydrate starting from $25{ }^{\circ} \mathrm{C}$ to $190{ }^{\circ} \mathrm{C}$. Above the reference Theophylline. 
Thermogravimetric analysis on TS3w (See Supplementary Materials, Figure S2) shows a two steps weight loss while increasing the temperature. The first step might represent the channel-water molecule $\mathrm{O} 3 \mathrm{~W}$, and the second step might be interpreted as the other two molecules leaving the system, according to the weight changes $(5.7 \%$ and $10.6 \%$, respectively). DSC thermogram (See Supplementary Materials, Figure S1) shows two endo peaks at $68.9^{\circ} \mathrm{C}$ and $89.6^{\circ} \mathrm{C}$, associated with the two events observed in the TGA. VT-XRPD experiment confirms that the structure remains intact at $70{ }^{\circ} \mathrm{C}$. As described above, the salt structure is disrupted only after all of the water molecules have abandoned the HB network $\left(>70{ }^{\circ} \mathrm{C}\right)$, which links Theophylline and Squarate together. The following exothermic event around $138{ }^{\circ} \mathrm{C}$ could be interpreted as the rearrangement of the molecules into the two pure components, see Figure 3. TS3w melting at $227.7^{\circ} \mathrm{C}$ corresponds to the melting point of the anhydrous form (See DSC thermogram of TSan in the Supplementary Materials, Figure S5) and it suggests a previous crystallization of TSan, potentially happening where the second exothermic peak $\left(170.5^{\circ} \mathrm{C}\right)$ can be detected.

A VH-XRPD (Variable Humidity-X-ray powder diffraction) experiment was also carried out. Theophylline and Squaric Acid (molar ratio 1:1) powders were mixed and exposed to $95 \%$ RH for 3 days (Figure 4).

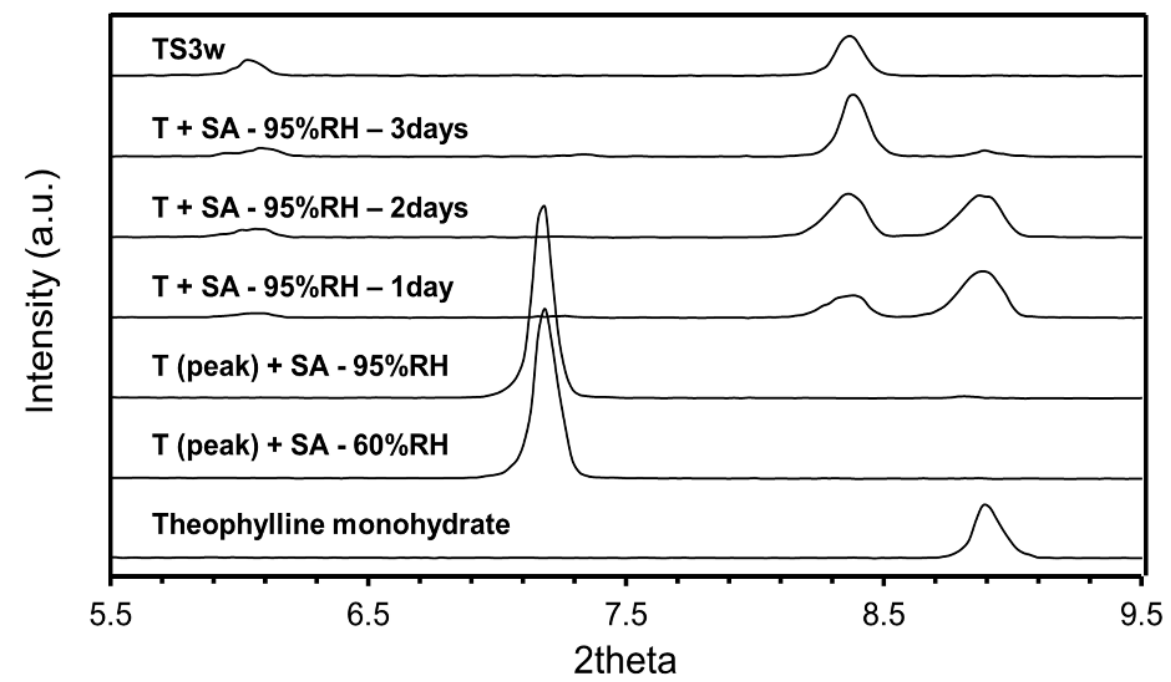

Figure 4. VH-XRPD of Theophylline (T) and Squaric Acid (SA). Below the reference Theo-phylline Monohydrate and above the reference Theophylline squarate trihydrate (TS3w).

This experiment confirmed the formation of the salts from the two components in the humidity chamber via a solid-state process without the need of dissolving the components in bulk solvents or applying energy from the milling processes. This observation is complementary to what was observed during the VT-XRPD experiment.

Furthermore, along with the formation of the salts, a steep increase in theophylline monohydrate was observed. After a few days though its signal started to drop while the peak of TS3w rose. It can thus be tentatively proposed that the formation of the theophylline monohydrate is a necessary step in the salt formation: as observed in $\mathrm{VH}$ XRPD of pure Theophylline (See Supporting Materials, Figure S9) the monohydrate process starts in less than four hours and is completed in $11 \mathrm{~h}$. The experiment never allowed us to see the complete conversion into the pure theophylline salt. That is probably due to the impossibility of mixing the powder during the experiment being the sample laid on a zero-background XRPD sample stage.

The salt formation has been confirmed also by the FTIR analysis showing the protonated nitrogen signal (See Supplementary Materials, Figure S7).

DVS shows that TS3w (See Supplementary Materials, Figure S3) might be considered a stable form since after a cycle of increasing and decreasing humidity, XRPD shows 
again the same pattern without any loss of crystallinity in the powder (See Supplementary Materials, Figure S4). That proved once again that the anhydrous form could be considered a metastable form.

Figure 5 shows the different powder patterns of commercial Theophylline, Squaric acid, Theophylline squarate trihydrate (TS3w), and Theophylline Squarate anhydrous (TSan). Thermogravimetric analysis on TSan does not show any significant weight loss (See Supplementary Materials, Figures S5 and S6).

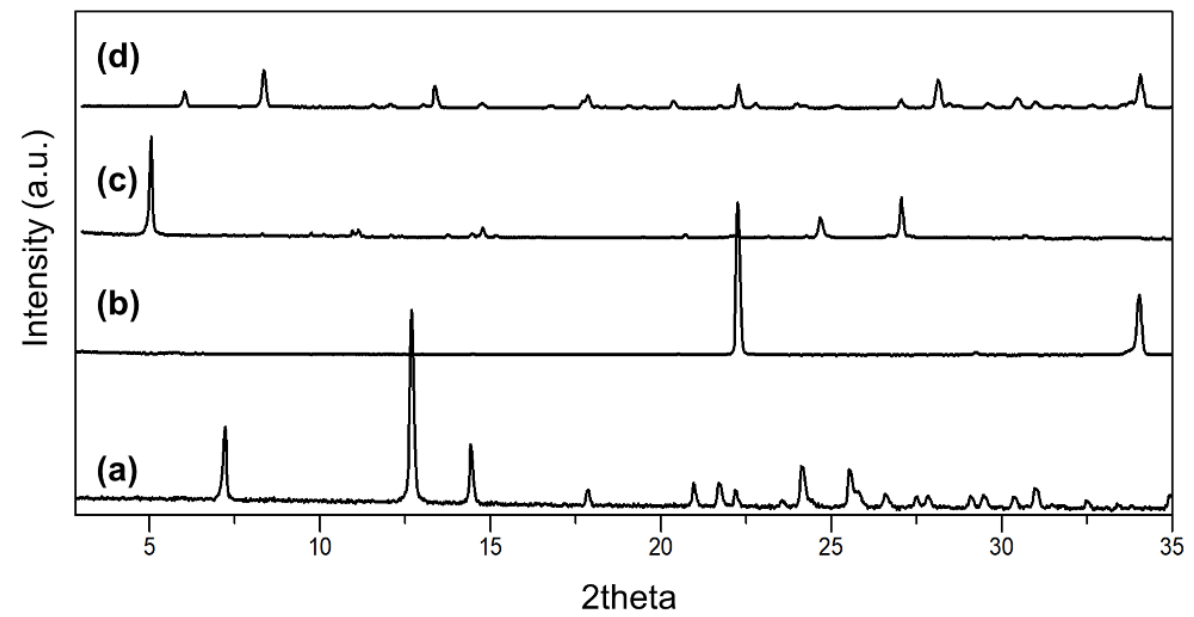

Figure 5. Powder X-ray diffraction of Theophylline (a), Squaric acid (b), Theophylline Squarate anhydrous (TSan, (c)) and Theophylline squarate trihydrate (TS3w, (d)).

\subsection{Dissolution Studies}

Dissolution studies were carried out to investigate whether the salification would have improved the pharmacokinetic profile in the dissolution step which is mandatory to have absorption of the API. Theophylline alone has an amazingly good bioavailability provided by a very fast and effective dissolution. Nevertheless, we were interested in a slower dissolution profile to better control the release of the drug into the blood stream. This would help to mild the adverse effect when approaching the therapeutic dose.

Those studies demonstrated a better dissolution profile of the salt compared with the free base (Figure 6) leading to a decrease of $52 \%$ at $2 \mathrm{~min}, 54 \%$ at $6 \mathrm{~min}$, and $38 \%$ at $15 \mathrm{~min}$ for TS3w. This valuable reduction might turn into an improved in-vivo performance allowing a better control of the administrated drug in terms of both therapeutic effects and adverse reactions. This is very useful in many cases, and it might even be essential when the therapeutic index is very narrow like in this case for Theophylline.

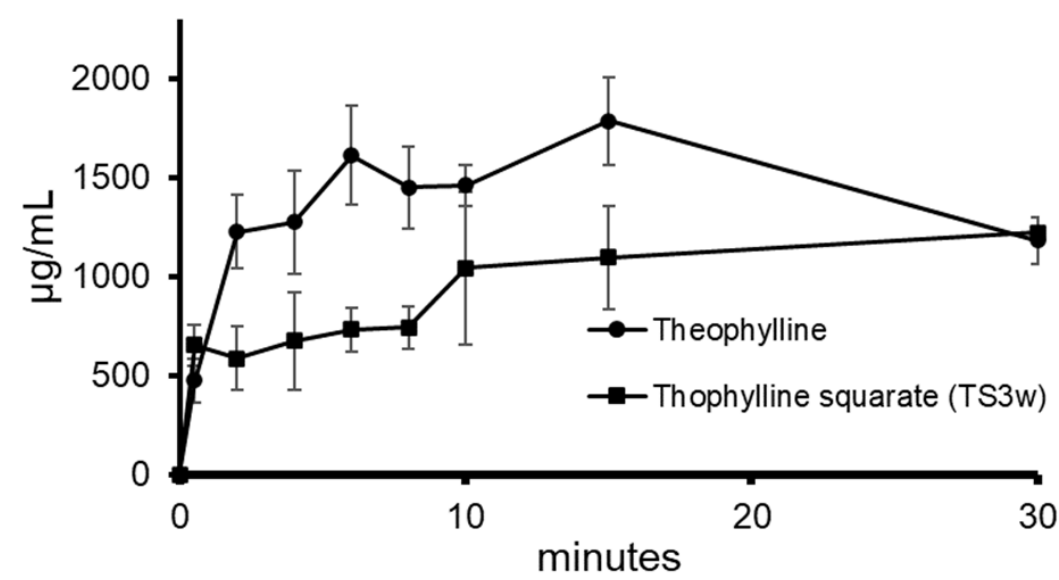

Figure 6. Dissolution study of Theophylline (squares) and Theophylline Squarate trihydrate (rounds). 


\section{Conclusions}

Theophylline salt was treated with squaric acid giving two different forms: anhydrous theophylline squarate and theophylline squarate trihydrate, whose crystal structure has been elucidated allowing to interpret its thermal behavior. Thermal analysis, VH-XRPD, and VT-XRPD experiments allowed us to characterize the stability of TS3w and the evolution of the various forms. Indeed, TS3w was stable until $70{ }^{\circ} \mathrm{C}$ and it dissociated into the two starting components only above $70^{\circ} \mathrm{C}$, making it suitable for a tablet manufacturing process for instance. Complementary, theophylline, and squaric acid alone led to the salt formation in a high $\mathrm{RH} \%$ ambient.

During the dissolution study, TS3w showed a relevant decrease in the percentage of drugs released in the vehicle. This allows a better control of the administrated dose, reducing the adverse effects without losing efficacy.

Salification of Theophylline can thus be considered a valuable strategy to modify its physio-chemical properties and it can be taken into account as an alternative method for controlled release of the drug.

Supplementary Materials: The following are available online at https: / www.mdpi.com/article/ 10.3390 / cryst12020201/s1, Table S1. Summary of crystallographic data for Theophylline Squarate trihydrate (TS3w); Figure S1. DSC thermogram of TS3w ; Figure S2. TGA thermogram of TS3w; Figure S3. DVS of TS3w; Figure S4. XRPD of TS3w after DVS (a) compared to its pattern before DVS (b); Figure S5. DSC thermogram of TSan; Figure S6. TGA thermogram of TSan. Figure S7. FTIR of Theophylline (red), Squaric Acid (black) and Theophylline squarate trihydrate (blue). Figure S8. Asymmetric unit of Theophylline squarate trihydrate (a) and molecular structure highlighting the HB connections and distances (b). Figure S9. VH-XRPD of pure Theophylline.

Author Contributions: Project administration, L.M., I.B., F.A. and A.B.; data curation, L.B. and L.F.; formal analysis, L.B. All authors have read and agreed to the published version of the manuscript.

Funding: This research was funded by Chiesi Farmaceutici S.p.A. (CHF-RES-00228).

Institutional Review Board Statement: Not applicable.

Informed Consent Statement: Not applicable.

Conflicts of Interest: The authors declare no conflict of interest.

\section{References}

1. Barnes, P.J. Theophylline. Am. J. Respir. Crit. Care Med. 2013, 188, 901-906. [CrossRef] [PubMed]

2. Focaroli, S.; Jiang, G.; O'connell, P.; Fahy, J.V.; Healy, A.M. The Use of a Three-Fluid Atomising Nozzle in the Production of Spray-Dried Theophylline/Salbutamol Sulphate Powders Intended for Pulmonary Delivery. Pharmaceutics 2020, $12,1116$. [CrossRef] [PubMed]

3. Barnes, P.J. Theophylline: New Perspectives for an Old Drug. Am. J. Respir. Crit. Care Med. 2003, 167, 813-818. [CrossRef] [PubMed]

4. Wang, Y.; Wang, C.Z.; Lin, K.X.; Qian, G.S.; Zhuo, W.L.; Li, S.P.; Zhao, Z.Q.; Liao, X.Q.; Song, Y.X. Comparison of Inhaled Corticosteroid Combined with Theophylline and Double-Dose Inhaled Corticosteroid in Moderate to Severe Asthma. Respirology 2005, 10, 189-195. [CrossRef] [PubMed]

5. Svedmyr, K. Effects of Oral Theophylline Combined with Oral and Inhaled B2-Adrenostimulants in Asthmatics. Allergy 1982, 37, 119-127. [CrossRef] [PubMed]

6. Pezoa, R.; Gai, M.N.; Gutierrez, C.; Arancibia, A. Development of a Controlled-Release Theophylline Tablet: Evaluation in Vitro and in Vivo. An. Real Acad. Farm. Inst. Espana 1992, 58, 269-283.

7. Rodrigues, M.; Peiriço, N.; Matos, H.; Gomes De Azevedo, E.; Lobato, M.R.; Almeida, A.J. Microcomposites Theophylline/Hydrogenated Palm Oil from a PGSS Process for Controlled Drug Delivery Systems. J. Supercrit. Fluids 2004, 29, 175-184. [CrossRef]

8. Jian, H.; Zhu, L.; Zhang, W.; Sun, D.; Jiang, J. Galactomannan (from Gleditsia Sinensis Lam.) and Xanthan Gum Matrix Tablets for Controlled Delivery of Theophylline: In Vitro Drug Release and Swelling Behavior. Carbohydr. Polym. 2012, 87, $2176-2182$. [CrossRef]

9. Buhecha, M.D.; Lansley, A.B.; Somavarapu, S.; Pannala, A.S. Development and Characterization of PLA Nanoparticles for Pulmonary Drug Delivery: Co-Encapsulation of Theophylline and Budesonide, a Hydrophilic and Lipophilic Drug. J. Drug Deliv. Sci. Technol. 2019, 53, 101128. [CrossRef] 
10. Hayashi, T.; Kanbe, H.; Okada, M.; Suzuki, M.; Ikeda, Y.; Onuki, Y.; Kaneko, T.; Sonobe, T. Formulation Study and Drug Release Mechanism of a New Theophylline Sustained-Release Preparation. Int. J. Pharm. 2005, 304, 91-101. [CrossRef]

11. Vranić, E. Basic Principles of Drug-Excipients Interactions. Bosn. J. Basic Med. Sci. 2004, 4, 56-58. [CrossRef] [PubMed]

12. West, R. History of the Oxocarbons, 1st ed.; Academic Press: New York, NY, USA, 1980; pp. 1-14. [CrossRef]

13. Horiuchi, S.; Tokunaga, Y.; Giovannetti, G.; Picozzi, S.; Itoh, H.; Shimano, R.; Kumai, R.; Tokura, Y. Above-Room-Temperature Ferroelectricity in a Single-Component Molecular Crystal. Nature 2010, 463, 789-792. [CrossRef] [PubMed]

14. Sreejith, S.; Carol, P.; Chithra, P.; Ajayaghosh, A. Squaraine Dyes: A Mine of Molecular Materials. J. Mater. Chem. 2008, 18, 264-274. [CrossRef]

15. Ajayaghosh, A. Chemistry of Squaraine-Derived Materials: Near-IR Dyes, Low Band Gap Systems, and Cation Sensors. Acc. Chem. Res. 2005, 38, 449-459. [CrossRef] [PubMed]

16. Palli, M.A.; McTavish, H.; Kimball, A.; Horn, T.D. Immunotherapy of Recurrent Herpes Labialis with Squaric Acid. JAMA Dermatol 2017, 153, 828-829. [CrossRef]

17. Chasák, J.; Šlachtová, V.; Urban, M.; Brulíková, L. Squaric Acid Analogues in Medicinal Chemistry. Eur. J. Med. Chem. 2021, 209, 112872. [CrossRef] [PubMed]

18. Schwartz, L.M.; Howard, L.O. Aqueous Dissociation of Squaric Acid. J. Phys. Chem. 1970, 74, 4374-4377. [CrossRef]

19. Karle, I.L.; Ranganathan, D.; Haridas, V. A Persistent Preference for Layer Motifs in Self-Assemblies of Squarates and Hydrogen Squarates by Hydrogen Bonding [X-H $\cdots \mathrm{O} ; \mathrm{X}=\mathrm{N}, \mathrm{O}$, or C]: A Crystallographic Study of Five Organic Salts. J. Am. Chem. Soc. 1996, 118, 7128-7133. [CrossRef]

20. Bertolasi, V.; Gilli, P.; Ferretti, V.; Gilli, G. General Rules for the Packing of Hydrogen-Bonded Crystals as Derived from the Analysis of Squaric Acid Anions: Aminoaromatic Nitrogen Base Co-Crystals. Acta Crystallogr. Sect. B Struct. Sci. 2001, 57, 591-598. [CrossRef]

21. Jurczak, E.; Mazurek, A.H.; Szeleszczuk, Ł.; Pisklak, D.M.; Zielińska-Pisklak, M. Pharmaceutical Hydrates Analysis-Overview of Methods and Recent Advances. Pharmaceutics 2020, 12, 959. [CrossRef]

22. Censi, R.; Di Martino, P. Polymorph Impact on the Bioavailability and Stability of Poorly Soluble Drugs. Molecules 2015, 20, 18759-18776. [CrossRef] [PubMed]

23. Buist, A.R.; Kennedy, A.R.; Manzie, C. Four Salt Phases of Theophylline. Acta Crystallogr. Sect. C Struct. Chem. 2014, 70, 220-224. [CrossRef] [PubMed]

24. Stevens, J.S.; Byard, S.J.; Schroeder, S.L.M. Salt or Co-Crystal? Determination of Protonation State by X-Ray Photoelectron Spectroscopy (XPS). J. Pharm. Sci. 2010, 99, 4453-4457. [CrossRef] [PubMed]

25. Mary Novena, L.; Suresh Kumar, S.; Athimoolam, S. Improved Solubility and Bioactivity of Theophylline (a Bronchodilator Drug) through Its New Nitrate Salt Analysed by Experimental and Theoretical Approaches. J. Mol. Struct. 2016, 1116, 45-55. [CrossRef]

26. Sarma, B.; Saikia, B. Hydrogen Bond Synthon Competition in the Stabilization of Theophylline Cocrystals. CrystEngComm 2014, 16, 4753-4765. [CrossRef]

27. Sheldrick, G.M. SADABS-2008/1-Bruker AXS Area Detector Scaling and Absorption Correction; Bruker AXS: Madison, WI, USA, 2008.

28. Sheldrick, G.M. SHELXT-Integrated Space-Group and Crystal-Structure Determination. Acta Crystallogr. Sect. A Found. Crystallogr. 2015, 71, 3-8. [CrossRef]

29. Sheldrick, G.M. Crystal Structure Refinement with SHELXL. Acta Crystallogr. Sect. C Struct. Chem. 2015, 71, 3-8. [CrossRef]

30. Dolomanov, O.V.; Bourhis, L.J.; Gildea, R.J.; Howard, J.A.K.; Puschmann, H. OLEX2: A Complete Structure Solution, Refinement and Analysis Program. J. Appl. Crystallogr. 2009, 42, 339-341. [CrossRef]

31. Allen, F.H.; Cruz-Cabeza, A.J.; Wood, P.A.; Bardwell, D.A. Hydrogen-Bond Landscapes, Geometry and Energetics of Squaric Acid and Its Mono- and Dianions: A Cambridge Structural Database, IsoStar and Computational Study. Acta Crystallogr. Sect. B Struct. Sci. Cryst. Eng. Mater. 2013, 69, 514-523. [CrossRef]

32. Fang, C.; Yang, P.; Liu, Y.; Wang, J.; Gao, Z.; Gong, J.; Rohani, S. Ultrasound-Assisted Theophylline Polymorphic Transformation: Selective Polymorph Nucleation, Molecular Mechanism and Kinetics Analysis. Ultrason. Sonochem. 2021, 77, 105675. [CrossRef] 